\title{
"Gender diversity and organizational performance: a study of IT industries in
}

Bangalore"

\begin{tabular}{|c|c|}
\hline AUTHORS & $\begin{array}{l}\text { Akanksha Khanna } \\
\text { Ashwini Y. } \\
\text { Jilsy Varghese }\end{array}$ \\
\hline ARTICLE INFO & $\begin{array}{l}\text { Akanksha Khanna, Ashwini Y. and Jilsy Varghese (2017). Gender diversity and } \\
\text { organizational performance: a study of IT industries in Bangalore. Innovative } \\
\text { Marketing, 13(3), 33-41. doi:10.21511/im.13(3).2017.04 }\end{array}$ \\
\hline DOI & http://dx.doi.org/10.21511/im.13(3).2017.04 \\
\hline RELEASED ON & Tuesday, 07 November 2017 \\
\hline RECEIVED ON & Friday, 29 September 2017 \\
\hline \multirow[t]{2}{*}{ ACCEPTED ON } & Tuesday, 31 October 2017 \\
\hline & $(\mathrm{cc}) \mathrm{EY}$ \\
\hline LICENSE & $\begin{array}{l}\text { This work is licensed under a Creative Commons Attribution } 4.0 \text { International } \\
\text { License }\end{array}$ \\
\hline JOURNAL & "Innovative Marketing " \\
\hline ISSN PRINT & $1814-2427$ \\
\hline ISSN ONLINE & $1816-6326$ \\
\hline PUBLISHER & LLC "Consulting Publishing Company "Business Perspectives" \\
\hline FOUNDER & LLC "Consulting Publishing Company "Business Perspectives" \\
\hline
\end{tabular}

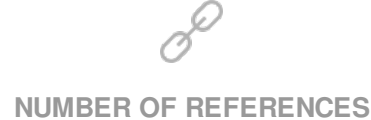

21

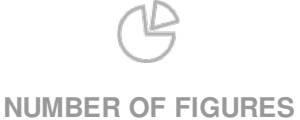

3

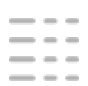

NUMBER OF TABLES

13

(C) The author(s) 2022. This publication is an open access article. 


\title{
Akanksha Khanna (India), Ashwini Y. (India), Jilsy Varghese (India) \\ Gender diversity and organizational performance: a study of IT industries in Bangalore
}

\begin{abstract}
Humans are considered to be different from each other with their acumen and intelligence. The working condition in IT sector has changed over the past few decades. There has been a drastic increase in the number of female employees towards the development of IT sector over the past few years. Gender diversity is creating a wide range of awareness and helps understand the importance of gender identity. IT industry which is a dominant industry in India has reckoned gender diversity as a major tool to ensure it stands on criteria of being competent and innovative in the ever changing dynamic business environment. The main objective of this paper is to analyze the relationship between acceptance of gender diversity among the employees, diversity practices and programs adopted by the IT industries and barriers to the same.
\end{abstract}

Keywords: gender diversity, gender identity, IT industry, diversity practices, diversity programs, obstacles, organizational performance.

JEL Classification: J16, M15.

Received on: $29^{\text {th }}$ of September, 2017.

Accepted on: $31^{\text {st }}$ of October, 2017.

\section{Introduction}

Human are considered to be different from each other with their skill and intelligence. The number of female employees in the workforce has dramatically increased in the past few decades. Many experts claim that accepting gender diversity is the right way to do business. According to World Bank (2002), women typically work about 25\% more hours than men, but their total remuneration is less. They are usually concentrated either in the rural areas or the informal sector of urban areas, where pay levels tend to be lower than in the formal sector of the economy (Faktörler \& Etkiler, 2014). As per surveys, Fortune 500 companies with more women on their boards tend to be more profitable. Women managers are considered to be more creative and are strong in their team building skills (Bibi \& Naima, 2015). It is essential to know the importance of gender diversity which can have an impact (positive or negative) on organizational performance.

Gender diversity is creating awareness and understanding the importance of gender identity. Treating men and women equally at the workplace is known as gender diversity at workforce it adds value to the company's bottom line where different opinion and ideas are generated. Women in the past were assigned only for temporary or part time work

(C) Limited Liability Company "Consulting Publishing Company "Business Perspectives", 2017.

Akanksha Khanna, Dr., Assistant Professor, Department of Commerce, Christ University, India.

Ashwini Y., Ms., Research Scholar, Department of Commerce, Christ University, India.

Jilsy Varghese, Ms., Research Scholar, Department of Commerce, Christ University, India. since they are not considered equal to men's performance. In some situations, women are likely to quit after marriage or after becoming pregnant since they are solely responsible to take care of children and family. But today the scenario has slightly changed where women continue to work even after marriage and children.

We chose to focus mainly on gender diversity, whereas gender, race/ethnicity, caste, and disability have been identified in previous literature in India (Kundu \& Mor, 2016). Further, gender, caste, and race/ethnicity provide a strong basis for social categorization of society (Shenoy, 2013), whereas gender and disability have been the major focus of the diversity efforts in Indian companies (Mercer, 2012). Thus, overall the study comprises males and females from various categories including caste: general category (upper and forward class), and socially disadvantaged (schedule castes (SCs); the scheduled tribes (STs); the other backward classes (OBCs); minority (Sikhs, Muslims, Christians, etc.); and disabled (handicapped, except mentally challenged).

\section{Need and the significance of the study}

In the context of Bangalore, it has become one of the main pillars of an Indian economy. Bangalore stands unique among all places in India in terms of revenue generated from software exports. Bangalore is known as "silicon valley of India", because the major software companies are in Bangalore. Though there have been several research studies done with regard to gender diversity, very few have focused on analyzing the relationship between acceptance of gender diversity among the employees, diversity practices and programs adopted by the IT industries and barriers to the same. 
This study attempts to fill out this research gap and also respond to Subhash C. Kundu and Archana Mor (2017) for research on gender diversity and organizational performance: a study of IT industry in India. For this purpose, IT industries like Infosys, Tata consultancy services, Accenture and Wipro were selected. The reason for choosing only these four companies is because these are the best among all the IT sectors compared to others and also it was feasible to collect data from these companies. The main reason for restricting to only these four companies was lack of time.

\section{Literature review}

Gender diversity means equal representation of male and female. Workplace diversity does not mean only to bring the different workforce to an organization. It also involves diversified talent to the organization (Bibi \& Naima, 2015). As females are working in a male dominated society and their set of procedure and practices will differ. Most of the times female face too many hurdles that minimize their space towards upper level. Success of an organization depends upon utilization of talented employees at best, irrespective of male or female (Bibi \& Naima, 2015). The most common gender stereotypes are related to communal and agentic associations. Women are generally associated with communal characteristics, while males are associated with agentic characteristics (Berkery, Morley, \& Tiernan, 2013). Lack of similarities between men and women perceptions relate to their receptivity of gender diversity and diversity management. There is an increased organizational performance by women when compared to men (Herd, Boyce, \& M, 2013).

Due to globalization and changes in economic and social conditions, the role and self-perception of women in industrialized countries is dramatically changing. The appearance of women in formerly allmale occupations contributes to this "dramatic cultural change" (Maznevski, Jonsen, \& L., 2003). While a general stereotype exists that men are better at navigating than women, experimental evidence indicates that men and women differ in their use of spatial strategies, and this preference determines gender differences (George, Rosenthal, Norman, p. Smith, \& MC, 2012). Stereotypes are perceptions about the qualities that distinguish groups or categories of people (Maznevski, Jonsen, \& L., 2003). Infosys has taken several measures to increase women employees from past 5 years (Buddhapriya, 2013). Estimates reveal that firms operating in complex environments and which have a high proportion or number of women officers did experience positive and significant abnormal returns of $0.17 \%$ monthly, intuitively amounting to a $6 \%$ return over a 3 -year period (Claude Francoeur, 2008).
Women's performance would be superior in the landmark than in the geometry task, but when compared to men, they would perform equally well in both. In addition, men's performance would be superior to that of females in the geometry task, but not in the landmark task (George, Rosenthal, Norman, Smith, \& MC, 2012). Women are found to be devalued in the leadership qualities to the great extent when compared with male (Herd, Boyce, \& M, 2013). Gender stereotypes exist within the workplace and affect the perception of male and female behavior within an organization in addition to the way in which males and females behave can be influenced by these stereotypes manner in which their behavior is evaluated (Nadler, Cameron, \& T., 2013). Companies which have adopted workforce diversity have significantly changed its performance towards rapid growth by creating new ideas, providing suggestion and even in solving problems (Ortiz \& Albert, 2013). A large number of studies have investigated the influence of board composition on the value of the firm. These have examined, among others, the percentage of insiders on the board (Campbell \& Minguez, 2008).

Leadership style of a man is different from that of a woman (Maher, 1997). Women were found to lead in a more interpersonally oriented way and men were found to lead in a more task oriented way (Eagly \& Johnson, 1997). Role of women changing due to globalization and social conditions despite these changes, beliefs in leadership of women roles seem to flourish across culture. Stereotype is an important barrier to women for attaining senior positions in business. They have to work harder than men to prove themselves (Kravitz, 2003). Gender differences and perceptions of such differences play a powerful role in maintaining the 'glass ceiling'. Women and men, who are exposed to gender stereotypes, also accept the existing gender inequalities (Jonsen \& Maznevski, 2010). Having more women on corporate board or on both corporate board and top management do not seem to generate significant more return. Thorough examination has been done comparing source of diversity in corporate governance and top management on a wider scale. Analysis has also been done to decide whether gender diversity can also enhance corporate performance (Frauncoeur, Labelle, \& Bernard, 2008). Early and Mosakowski state that there are arguments that generate gender diversity may serve to reduce firm performance. The performance of an employee's depends mainly on gender, because women contribute more than men in terms of profit and production (Kravitz, 2003). The issue of gender equality has risen up the political agent. More women are attracted to serve on company boards which require them to have the 
educational opportunities and skills necessary to compete with male counterparts (Compbell \& VeraMinguez, 2008). Women are more likely to be represented in less competitive and less prestigious positions. Service in high-status offices is thought to conflict with sex-role socialization and family responsibilities. Merit selection systems in particular are designed to reduce the emphasis on patronage and public opinion (Bratton \& Spill, 2002).

\section{Objectives of the study}

The main objective of this paper is to analyze the relationship between acceptance of gender diversity among the employees, diversity practices and programs adopted by the IT industries and barriers to the same. The study examines the various barriers in IT sector in India, specifically Bangalore and how these factors influence on the employees from gender diversity perspective. Keeping in mind the above points, the objectives of the study are as follows:

- to identify whether employees of different gender differ in the perception regarding equal representation of developmental opportunities;

- to examine the relationship between gender diversity acceptance and barriers to same;

- to access whether employees differ in perception regarding promotion of gender diversity.

Acceptance to gender diversity. This explains the employee perception of the importance of diversity and their attitude towards gender diversity. For the purpose of this paper, accepting the similarities and dissimilarities with respect to opposite gender workers that has been observed in 4 IT sector companies namely Infosys, Wipro, TCS and Accenture located in Bangalore region have been taken into consideration.

Obstacles to gender diversity. This refers to the factors which create roadblocks to gender diversity in the dynamic work environment.

Gender diversity management programs and practices. It refers to the organization policies, system and practices that are conductive to employees of different gender groups. It explains how strongly the company is practicing to initiating the gender diversity programs and policies within an organization.

\section{Research design}

The research adopts both exploratory and descriptive design for structuring the research process. HR managers of four IT selected sectors were approached to get opinion about diversity management practices and obstacles present in companies. A five point Likert rating scale was used to record survey response and these questionnaires were administered among respondents to collect data for the research ranging from $1=$ strongly disagree, $2=$.disagree, $3=$ satisfactory, $4=$ agree and $5=$ strongly agree.

4.1. Sampling population. A sample of 250 respondents was included in the current study. To collect these data, around 275 questionnaires were administered among 4 IT sector employees, constituting both male and female employees. After examining, out of 275,25 responses were not considered owing to incomplete information filled by the respondents. Finally, 250 responses from the employees of Infosys, Wipro, TCS and Accenture were collected in equal proportion to supplement information for the survey.

4.2. Data collection. The primary data have been collected from IT companies based out of Bangalore namely Infosys, Wipro, Accenture and Tata consultancy Services. The sample size for the study is 250. Personal interview, Google forms and e-mails were used for data collection in the current study. Secondary data have been collected by company websites, journals related to Information Technology Sector, websites related to IT sectors.

4.3. Data analysis. The analysis of data was done using following statistical tools.

1. Cronbach's alpha for reliability test.

2. Pearson's correlations.

3. Multiple regression analysis.

4. Two-way ANOVAs.

The Cronbach's alpha coefficient for the pilot test and for the total sample were obtained and values range from 0.88-0.9, indicating a high level of inter item consistency and reliability for the variables.

4.4. Hypotheses. Based on the objectives of the study three hypotheses were formed to investigate empirically.

H1: There are significant differences between gender perceptions regarding equal representation of developmental opportunities.

$\mathrm{H} 2$ : There is significant relation between acceptance of gender diversity and gender diversity management programs and practices.

H3: There is significant relationship between acceptance of gender diversity and barriers to the same.

The analysis was done using statistical analysis tool SPSS version 16. 


\subsection{Demographic descriptive statistics.}

Table 1. Frequency and percentage of employees with respect to gender

\begin{tabular}{|l|c|c|c|c|}
\hline \multicolumn{1}{|c|}{ Gender of employees } & Frequency & Percent & Valid percent & Cumulative percent \\
\hline Male & 100 & 40 & 40 & 40 \\
\hline Female & 150 & 60 & 60 & 100 \\
\hline Total & 250 & 100 & 100 & \\
\hline
\end{tabular}

Table 2. Frequency and percentage of employees with respect to age group

\begin{tabular}{|l|c|c|c|c|}
\hline \multicolumn{1}{|c|}{ Age of the employees } & Frequency & Percent & Valid percent & Cumulative percent \\
\hline $18-25$ & 60 & 24 & 24 & 24 \\
\hline $26-35$ & 50 & 20 & 20 & 44 \\
\hline $36-45$ & 80 & 32 & 32 & 76 \\
\hline $46-60$ & 60 & 24 & 24 & 100 \\
\hline Total & 250 & 100 & 100 & \\
\hline
\end{tabular}

Table 3. Frequency and percentage of employees with respect to education

\begin{tabular}{|l|c|c|c|c|}
\hline \multicolumn{1}{|c|}{$\begin{array}{c}\text { Education status of } \\
\text { employees }\end{array}$} & Frequency & Percent & Valid percent & Cumulative percent \\
\hline Undergraduate & 150 & 60 & 60 & 60 \\
\hline Postgraduate & 80 & 32 & 32 & 92 \\
\hline Above post-graduation & 20 & 8 & 8 & 100 \\
\hline Total & 250 & 100 & 100 & \\
\hline
\end{tabular}

Table 4. Frequency and percentage of employees with respect to income

\begin{tabular}{|l|c|c|c|c|}
\hline \multicolumn{1}{|c|}{ Income of employees } & Frequency & Percent & Valid percent & Cumulative percent \\
\hline Below 10000 & 40 & 16 & 16 & 16 \\
\hline $10000-25000$ & 90 & 36 & 36 & 52 \\
\hline $25000-50000$ & 108 & 43.2 & 43.2 & 95.2 \\
\hline 50000 and above & 12 & 4.8 & 4.8 & 100 \\
\hline Total & 250 & 100 & 100 & \\
\hline
\end{tabular}

Table 5. Frequency and percentage of employees with respect to type of company

\begin{tabular}{|l|c|c|c|c|}
\hline \multicolumn{1}{|c|}{ Type of the company } & Frequency & Percent & Valid percent & Cumulative percent \\
\hline Infosys & 80 & 32 & 32 & 32 \\
\hline Accenture & 70 & 28 & 28 & 60 \\
\hline Wipro & 50 & 20 & 20 & 100 \\
\hline Total & 250 & 100 & 100 & \\
\hline
\end{tabular}

\section{Empirical results and analysis}

Table 6. Reliability statistics

\begin{tabular}{|c|c|}
\hline Cronbach's alpha & N of items \\
\hline 0.868 & 24 \\
\hline
\end{tabular}

Cronbach's alpha - it is a statistical tool used for the reliability test and the total sample were obtained with a value of 0.868 , indicating a high level of inter item consistency for the variables.

5.1. Acceptance of gender diversity. The descriptive statistics for variable acceptance of gender diversity, the eight factors were taken into consideration Table 7 and Fig. 1 represents the responses of 250 employees of IT sector.

Table 7. Acceptance of gender diversity

\begin{tabular}{|c|c|c|c|}
\hline & N & Mean & Std. deviation \\
\hline 1. Organization gives a comfortable environment to work with the boss regardless of gender diversity. & 250 & 2.01 & .929 \\
\hline 2. Organization encourages effective communication regardless of gender diversity. & 250 & 1.97 & .932 \\
\hline 3. I'm comfortable to work with both genders. & 250 & 1.77 & 1.102 \\
\hline 4. I value others regardless of the gender. & 250 & 1.80 & 1.068 \\
\hline 5. I can learn new skills, values working with people of other gender. & 250 & 1.93 & 1.064 \\
\hline 6. I value and respect fundamental differences with respect to gender. & 250 & 1.76 & .830 \\
\hline 7. Gender quota policy is necessary from recruitment to retainment. & 250 & 3.14 & 1.277 \\
\hline 8. There is no difference in work performance of both genders. & 250 & 2.17 & 1.149 \\
\hline
\end{tabular}




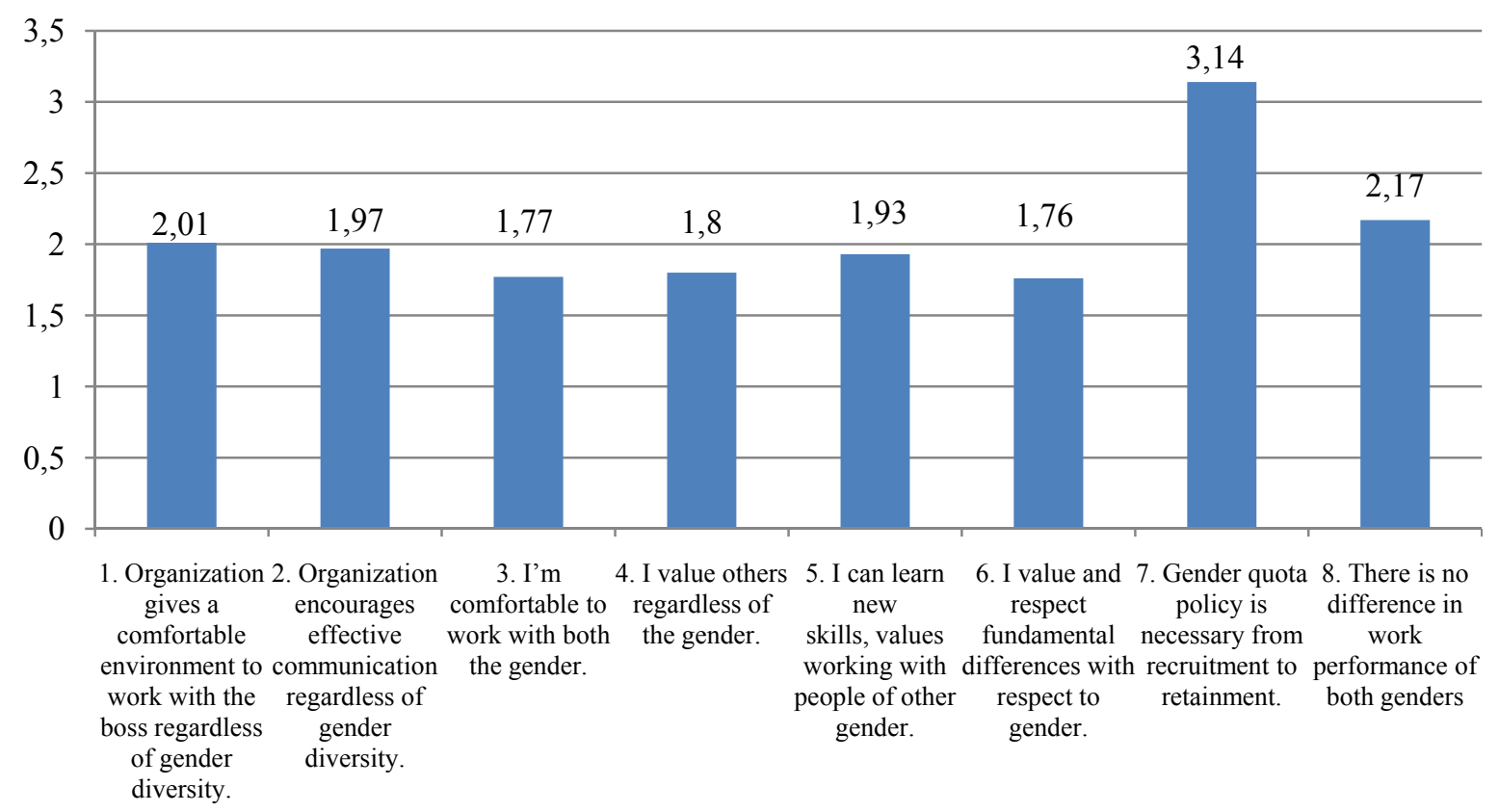

Fig. 1. Acceptance of gender diversity

5.1.1. Interpretation. Table 7 and Fig. 1 explain the opinion of IT employees towards acceptance of gender diversity in an organization. The mean and SD were calculated for the eight variables from the responses. The result indicated that responses were strongly agreed for the statement, that there is a requirement of gender quota policy in organization by the both the gender in acceptance of gender diversity (mean = 3.14). They also agreed that there is no difference in the work performance by both genders (mean $=2.17$ ). The respondents' agreed that organizations gives a comfortable workplace regardless of gender (mean $=$ 2.01). Surprisingly responses were neutral to the statement that, organization encourages effective performance by both the gender and they can learn new skill, value at workplace (mean $=1.97$ and 1.93 ), respectively. The respondent's acceptability to three (3) items is very low, i.e., they are comfortable to work with both the gender $($ mean $=1.77)$. They value and respect fundamental difference irrespective of gender (mean=1.76) and they value others regardless of gender diversity (mean $=1.8$ ). It can be interpreted that though respondents are accepting gender quota policy is necessary from recruitment to retainment. They are not agreeing that they value and respect others regardless of gender. The respondents are not positively agreeing that they are comfortable to work with both genders. The overall mean for all the eight (8) items for acceptance of gender diversity is 2.069 .

\subsection{Gender diversity management programs} and practices. Four items /factors describe the gender diversity management programs and practices. The mean and standard deviation represents the overall responses towards programs and practices adopted by IT sector in Bangalore.

Table 8 . Gender diversity management programs and practices

\begin{tabular}{|c|c|c|c|}
\hline & $\mathrm{N}$ & Mean & Std. deviation \\
\hline 9. Workplace conducts gender diversity workshops and seminars. & 250 & 2.60 & 1.118 \\
\hline 10. There is enough involvement and commitment by top management on gender diversity programs. & 250 & 2.54 & 1.066 \\
\hline 11. There is protection against gender discrimination. & 250 & 2.29 & 1.143 \\
\hline 12. There are options for flexible working hours. & 250 & 2.48 & 1.066 \\
\hline 13. Mentoring, coaching and counseling sessions are there for career development. & 250 & 2.31 & 1.027 \\
\hline $\begin{array}{l}\text { 14. Gender diversity training sessions are conducted to enhance awareness about gender equality } \\
\text { and to remove gender bias issues. }\end{array}$ & 250 & 2.39 & 1.103 \\
\hline
\end{tabular}




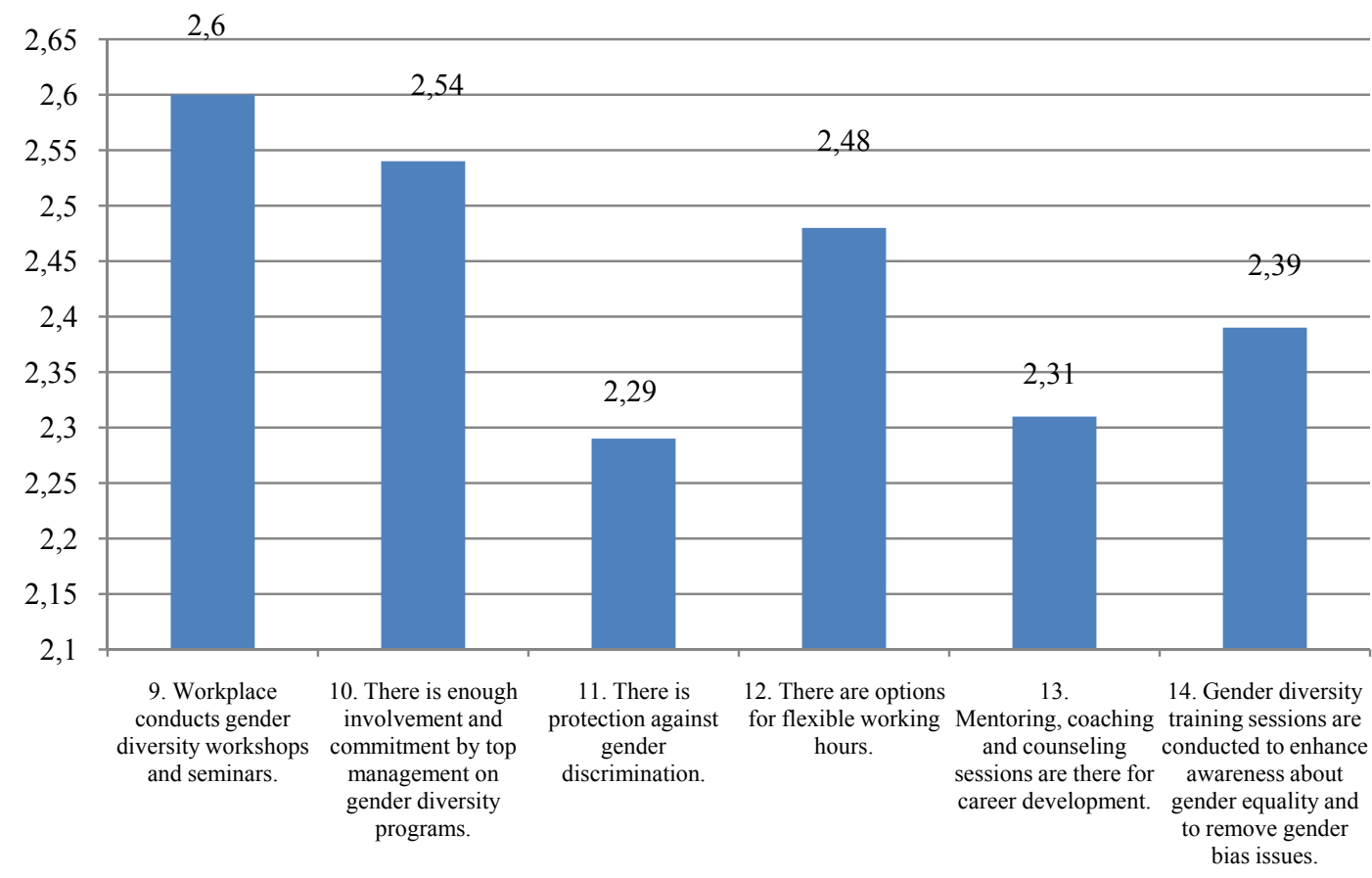

Fig. 2. Gender diversity management programs and practices

5.2.1. Interpretation. Table 8 and Fig. 2 show the response of respondents about their perception regarding gender diversity management programs and practices have been initiating in organizations. It has been found that employees of IT sector have strongly agreed for two variables, i.e., workplace conducts gender diversity workshops and seminars $($ mean $=2.6)$ and there is enough involvement and commitment by top management on gender diversity programs (mean $=2.54$ ). Employees have also agreed for the statement that there is option for flexible working hours (mean $=2.48$ ). The respondents have reacted neutral for two items i.e. Gender diversity training sessions are conducted to enhance awareness about gender equality and to remove gender bias issues (mean $=2.39$ ). And they feel the same for mentoring, coaching and counseling sessions are there for career development statement (mean $=2.31$ ). Comparatively, respondents have reacted negatively to one factor respondent's feel there is no protection against gender discrimination (mean $=2.29$ ). It can be interpreted as employees are strongly agreed that the company has enough coaching, mentoring session, but there is less awareness about the programs related to protection against gender discrimination. The overall mean for six (6) variables is 2.43 .

5.3. Obstacles to gender diversity. The six items describe independent variable i.e., obstacles to gender diversity Table 9 and Fig. 3 represent the total responses of 250 IT employees in Bangalore.

Table 9. Obstacles to gender diversity

\begin{tabular}{|c|c|c|c|}
\hline & $\mathrm{N}$ & Mean & Std. deviation \\
\hline 15. Gender discrimination is there in promotion and career development opportunities. & 250 & 2.79 & 1.223 \\
\hline 16. Workplace gives opportunities for higher position for 2 employees. & 250 & 2.58 & 1.166 \\
\hline 17. There are policies which favor masculine or patriarchal corporate culture. & 250 & 2.77 & 1.130 \\
\hline 18. Workplace provides developmental opportunities for women employees. & 250 & 2.33 & .985 \\
\hline 19. You have led projects in the organization. & 250 & 2.71 & 1.163 \\
\hline 20. Management is open to participative decision making from all the employees on a fair bias. & 250 & 2.50 & 1.195 \\
\hline
\end{tabular}




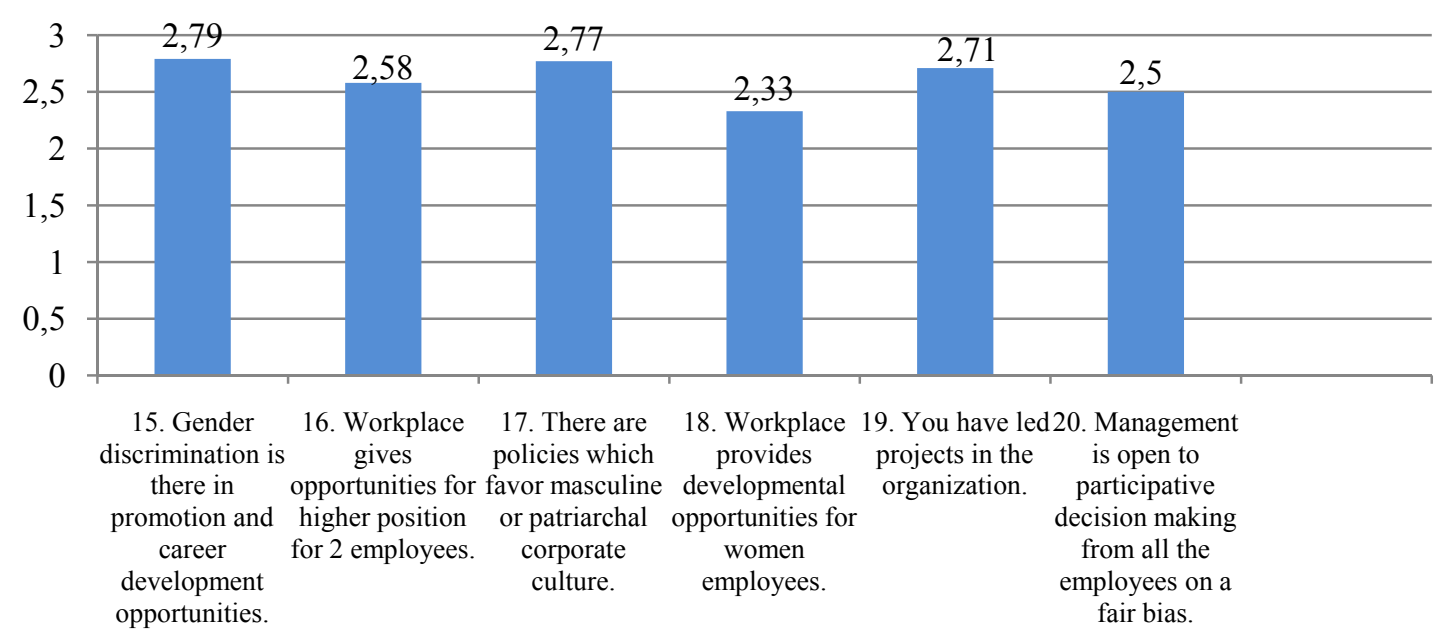

Fig. 3. Obstacles to gender diversity

5.3.1. Interpretation. Table 9 and Fig. 3 represent the six (6) variables to be considered as obstacles to gender diversity. Results shows that respondents have strongly agreed that gender discrimination in promotion and career development opportunities are obstacles for the growth of gender diversity in the organization (mean $=2.79$ ), respondents have also agreed for two (2) items, i.e., there are policies which favor masculine or patriarchal corporate culture and they have led projects in the organization are the prominent obstacles to gender diversity mean $=2.77$ and 2.71 , respectively). The neutral opinion is obtained for the statement workplace gives opportunities for higher position for female employees (mean $=2.58$ ) and Management is open to participative decision making from all the employees on a fair bias (mean $=2.5$ ). They have negatively reacted thatworkplace provides developmental opportunities for women employees with a mean of 2.33. The SD for majority of the items is on the higher side reflecting that the responses are inconsistent and slightly deviated from the mean values. Thus, it can be interpreted as employees perceive medium level of barriers to gender diversity in the organization. The overall mean for six (6) items is 2.61 .

Table 10. Correlation coefficient for variables

\begin{tabular}{|l|c|c|c|c|}
\hline & & $\begin{array}{c}\text { Acceptance of gender } \\
\text { diversity }\end{array}$ & $\begin{array}{c}\text { Gender diversity management } \\
\text { practices and programs }\end{array}$ & $\begin{array}{c}\text { Obstacles to gender } \\
\text { diversity }\end{array}$ \\
\hline \multirow{3}{*}{$\begin{array}{l}\text { Acceptance of gender } \\
\text { diversity }\end{array}$} & Pearson correlation & 1 & -0.590 & 0.100 \\
\cline { 2 - 5 } & Significant (2 tailed) & & 0.000 & 0.000 \\
\cline { 2 - 5 } $\begin{array}{l}\text { Gender diversity } \\
\text { management practices and } \\
\text { programs }\end{array}$ & $\mathrm{N}$ & 250 & 250 & 250 \\
\hline \multirow{3}{*}{\begin{tabular}{l} 
Obstacles to gender diversity \\
\cline { 2 - 5 }
\end{tabular}} & Pearson correlation & -0.590 & 1 & 0.272 \\
\cline { 2 - 5 } & Significant (2 tailed ) & 0.000 & 250 & 0.000 \\
\cline { 2 - 5 } & Significant (2 tailed ) & 250 & 0.272 & 250 \\
\cline { 2 - 5 } & $\mathrm{N}$ & 0.100 & 0.000 & 1 \\
\hline
\end{tabular}

Note: ** Correlation is significant at the 0.01 level (2-tailed).

Table 11. Regression model for the independent factor like programs and practices, obstacles to gender diversity on acceptance of gender diversity

\begin{tabular}{|c|c|c|c|c|c|c|}
\hline Model & Variables entered & $\begin{array}{l}\text { Variables } \\
\text { removed }\end{array}$ & $\mathrm{R}$ & R square & $\begin{array}{l}\text { Adjusted R } \\
\text { square }\end{array}$ & $\begin{array}{l}\text { Std. error of the } \\
\text { estimate }\end{array}$ \\
\hline & Gender diversity programs and practices & \multirow{2}{*}{---} & \multirow{2}{*}{0.593} & \multirow{2}{*}{0.380} & \multirow{2}{*}{0.379} & \multirow{2}{*}{0.17771} \\
\hline & Obstacles to gender diversity & & & & & \\
\hline
\end{tabular}

Note: a. Predictors: (constant), gender diversity management practices and programs and obstacles to gender diversity. 
Table 12. ANOVA outcomes for acceptance of gender diversity

\begin{tabular}{|c|c|c|c|c|c|c|}
\hline \multicolumn{2}{|c|}{ Model } & Sum of squares & df & Mean squared & F & significant \\
\hline \multirow{3}{*}{2} & Regression & 18.805 & 2 & 9.4025 & 130.889 & 0.030 \\
\cline { 2 - 7 } & Residual & 23.286 & 129 & 0.1805 & & \\
\cline { 2 - 8 } & Total & 42.091 & 131 & & & \\
\hline
\end{tabular}

Notes: a. Predictors: (constant), gender diversity management practices and programs and obstacles to gender diversity.

b. Dependent variables: acceptance of gender diversity.

Table 13. Coefficients

\begin{tabular}{|l|c|c|c|c|c|}
\hline \multirow{2}{*}{ Model 2 } & \multicolumn{2}{|c|}{ Unstandardized coefficients } & Standardized coefficients & & \\
\cline { 2 - 6 } & $\mathrm{B}$ & Std. error & Beta & $\mathrm{t}$ & Sig. \\
\hline Constant & 3.741 & 0.160 & & 19.91 & 0.000 \\
\hline Gender diversity management practices and programs & 0.076 & 0.036 & 0.073 & 1.067 & 0.023 \\
\hline Obstacles to gender diversity & -0.329 & 0.018 & -0.715 & -18.489 & 0.000 \\
\hline
\end{tabular}

Note: a. Dependent variables: acceptance of gender diversity.

\section{Discussion}

The Pearson correlation matrix obtained for the three variables is shown in output table 1.10. From the result, we derived that the acceptance to gender diversity is negatively correlated to obstacles to gender diversity and it is significant. The acceptance of gender diversity is positively and significantly correlated to gender diversity management and practices. This indicates that higher the diversity programs will result in lower acceptance, considering control over other variables, i.e., diversity management programs and practices.

The regression analysis has been explained by the other three Tables 11, 12 and 13. Regression model results are showed in Table 11, and $\mathrm{R}$ value $(0.380)$ is the correlation of this two variables with dependent variable are also included. The regression model explains $38 \%$ of the variation (value of $\mathrm{R}$ square is 0.380 ).

The ANOVA is computed and results are displayed in Table 12, and $\mathrm{F}$ value is 130.889 and it is significant (p-value is 0.000 and it is lower than 0.05). In the $\mathrm{df}$ (degree of freedom), the tables show that the first column represents the number of variables (2), the second number (249) is the total number of all the respondents for all the items $(\mathrm{N})$, minus is the number of items $(\mathrm{K})$ minus $1[(\mathrm{~N}-\mathrm{K}-1)=249]$. The F statistical produced $(\mathrm{F}=130.889)$ is significant at the 0.00 level. Hence both the null hypotheses were rejected.

Hence, we can interpret that, there is significant relationship between acceptance of gender diversity and gender diversity management programs and practices.

Table 13 shows influence of independent variables. If we look at value of beta coefficients, which resulted in highest number, i.e., 0.715 for the obstacles to gender diversity, which is significant at 0.000 levels. This implies that gender diversity management programs and obstacles to gender diversity are significant influencing acceptance of gender diversity (beta value are 0.073 and $-0.715, p<0.05$ and $t>\neq 1.96$ ). Gender diversity obstacles are influencing higher than gender diversity management programs and practices. Obstacles to gender diversity derived have significant negatively effecting the objective, i.e., acceptance of gender diversity among the employees of IT sector. From the regression model, constant value is 3.741 and coefficient obtained is 0.086 and -0.329 for independent variables. The regression equation is

$\mathrm{Y}_{1}=3.741+(0.086) \mathrm{X}_{1}-(-0.329) \mathrm{X}_{2}$,

where $\mathrm{Y}_{1}=$ acceptance of gender diversity (it's a dependent variable);

$\mathrm{X}_{1}=$ gender diversity management programs and practices (it's an independent variable);

$\mathrm{X}_{2}=$ obstacles to gender diversity (it's an independent variable).

The regressions equation helps in finding the relationship between gender diversity programs and obstacles to gender diversity. Hence, gender diversity programs will have positive and significant impact on acceptance of gender diversity in an organization. The regression model explains that obstacle have more negative impact on acceptance of gender diversity. Thus employees should focus on reducing the obstacles present in an organization to enhance the affectivity of gender diversity with regards to acceptance in an organization.

\section{Conclusion}

On the basis of the various empirical tests conducted, the relationship between barriers and acceptance of gender diversity is significant. Barriers to gender diversity have a negative influence on acceptance of gender diversity. Gender diversity programs will have positive and significant impact on acceptance of gender diversity in an 
organization. Significant relationship was found between various gender diversity programs and its acceptance at workplace.

However, there are some issues which could not be taken up in this study and hence can be considered worthwhile for future researchers to investigate these issues. These include:

1. The present study is based on the responses given by IT employees confined to Bangalore region only. Future studies can be conducted to include a broader perspective by including other regions of the country.
2. The present study only covers a minimum sample of 250 respondents and, hence, the sample may not be a true pointer of the entire universe and a larger sample size may be considered for future research,

3. The current study focuses on gender diversity across IT sector only. It will be worthwhile if other sectors are taken into consideration such as FMCG, Manufacturing, etc., and a comparative analysis be made among the same.

\section{References}

1. Berkery, E., Morley, M., \& Tiernan, S. (2013). Beyond gender role stereotypes and requisite managerial characteristics. Gender in Management: An International Journal, 278-298. Retrieved from http://www.emeraldinsight.com/doi/full/10.1108/GM-12-2012-0098

2. Bibi, \& Naima. (2015). Role of Gender Diversity in Organizational Effectiveness and its Implications. International Review of Management and Marketing, 80-85. Retrieved from http://www.econjournals.com/index.php/irmm/article/view/2469

3. Bratton, K. A., \& Spill, R. (2002). Existing Diversity and judicial selection: The role of the appointment method in establishing gender diversity in state supreme courts. Social Science Quaterly, 504-518. Retrieved from http://www.jstor.org/stable/42955803

4. Buddhapriya, S. (2013). Diversity Management Practices in Select Firms in India: A Critical Analysis. Journal of Business Ethics, 597-610. Retrieved from http://www.jstor.org/stable/23509817

5. Campbell, K., \& Mínguez, A. (2008). Gender Diversity in the Boardroom and Firm Financial Performance. Journal of Business Ethics, 435-451.

6. Claude Francoeur, R. L. (2008). Gender Diversity in Corporate Governance and Top Management. Journal of Business Ethics, 83-95. Retrieved from http://www.jstor.org/stable/25482199

7. Compbell, K., \& Vera-Minguez, A. (2008). Gender diversity in the Boardroom and firm financial performance. Journal of business ethics, 83, 435-451. Retrieved from http://www.jstor.org/stable/25482388

8. Eagly, \& Johnson. (1997). Gender related stereotype of transformational and transactional leadership.

9. Faktörler, K. L.-K., \& Etkiler, İ. K. (2014). Socio-Cultural Factor As Determinant of Female Leadership Quality. Implications for Human Resource Development, 53-62.

10. Frauncoeur, C., Labelle, R., \& Bernard, D.-S. (2008). Gender diversity in corporate governance and top management. Journal of business, 83-95.

11. Maher, K. J. (1997). Gender related stereotype of transformational and transactional leadership. Sex Roles, 37(3-4), 209-225.

12. Rosenthal, H. E., Norman, L., Smith, S. P, \& McGregor, A. (2012). Gender-Based Navigation Stereotype Improves Men's Search for hidden goal (pp. 682-695).

13. Boyce, L. A., \& Herd, M. A. (2013). A relationship between gender role stereotypes and requisite military leadership characteristics. Journal of Business Ethics, 365-378.

14. Jonsen, K., \& Maznevski, M. L. (2010). Gender differences in leadership-believing is seeing:implications for managing diversity. Equality, Diversity and Inclusion: An International Journal, 549-572.

15. Kravitz, D. A. (2003). More Women in the Workplace: Is There a Payoff in Firm Performance? (pp. 148149). Retrieved from http://www.jstor.org/stable/4165991

16. Kundu, S., \& Mor, A. (2016). Effect of diversity management on employees' organisational commitment: a study of Indian organization (pp. 16-22).

17. Maznevski, K., \& Jonsen, L. M. (2003). Gender differences in leadership -believing is seeing: implications for managing diversity. Journal of Business Ethics, 549-572. Retrieved from http://www.emeraldinsight.com

18. Mercer. (2012). Diversity and inclusion: an Asia Pacific perspective.

19. Nadler, S. M., \& Cameron, T. J. (2013). Gender roles and organizational citizenship behaviors: effects on managerial evaluation. Journal of Business Ethics, 380-398. Retrieved from http://www.emeraldinsight.com/doi/abs/10.1108/GM-10-2012-0074

20. Ortiz, \& Albert. (2013). Workforce Diversity: Diversity in Puerto Rico's Local Companies. Journal of Business Ethics, 67-68.

21. Shenoy, D. (2013). Courting substantive equality: employment discrimination law in India (pp. 453-465). 